\title{
Adjuvant Treatment of Breast Cancer with Taxanes
}

\author{
Catharina Wenzel Günther G. Steger \\ Department of Internal Medicine I, Clinical Division of Oncology, Medical University of Vienna, Austria
}

\section{Key Words}

Breast cancer - Paclitaxel - Docetaxel .

Chemotherapy, adjuvant

\section{Summary}

Adjuvant chemotherapy plays a significant role in improving survival in patients with breast cancer. So far, anthracycline-based combination chemotherapy regimens have demonstrated an advantage over standard cyclophosphamide, methotrexate and 5-fluorouracil (CMF) in the adjuvant treatment of breast cancer. The taxanes docetaxel and paclitaxel are 2 of the most active cytotoxic agents and are now under investigation in the adjuvant setting in a large series of randomized clinical trials that will enroll no less than 56,000 women of whom 22,000 women will contribute to paclitaxel-related questions and 34,000 to docetaxel-related questions. However, the optimal patient population for receiving a taxanecontaining adjuvant therapy regimen is still to be evaluated. The use of taxanes in sequence or in combination with anthracyclines is justified in the presence of nodepositive, estrogen receptor-negative tumors, HER2 overexpression or contraindications for the use of anthracyclines. A recommendation concerning optimal taxane schedules cannot be made yet.

\section{Introduction}

Adjuvant chemotherapy for breast cancer has undergone a major change over the past 2 decades. Results of the published update of the overview analysis by the Early Breast Cancer Trialist's Collaborative Group (EBCTCG) [1] indicate that

\author{
Schlüsselwörter \\ Brustkrebs · Paclitaxel · Docetaxel . \\ Chemotherapie, adjuvante
}

\section{Zusammenfassung}

Die adjuvante Chemotherapie ist fester Bestandteil in der Therapie des Mammakarzinoms. Die lange applizierte adjuvante Standardtherapie Cyclophosphamid, Methotrexat und 5-Fluorouracil (CMF) musste den überlegenen anthrazyklinhaltigen Kombinationsregimen weichen. Neue, in der Therapie des metastasierten und primären Mammakarzinoms aktive zytostatische Substanzen wie die Taxane, Docetaxel und Paclitaxel, werden derzeit in vielen adjuvanten Studienprotokollen untersucht. Dazu werden mehr als 56,000 an Brustkrebs erkrankte Frauen behandelt - 22,000 in Studien mit Paclitaxel und 34,000 in Studien mit Docetaxel. Jedoch muss noch die optimale Patientenpopulation, die von einer taxanhaltigen adjuvanten Therapie profitieren würde, evaluiert werden. Der Einsatz von Taxanen in sequentieller oder kombinierter Applikation mit Anthrazyklinen ist nach derzeitigem Wissen bei lymphknotenpositiven, östrogenrezeptornegativen Tumoren, bei HER2-Überexpression oder bei bestehender Kontraindikation gegen Anthrazykline notwendig. Jedoch sind auch noch weitere Studien zur Bestimmung des besten Taxanprotokolls notwendig.

administration of adjuvant chemotherapy significantly reduced the risk of recurrence by $23.5 \%$ and the risk of death by $15.3 \%$. According to the same overview, the 10 -year recurrence-free survival for node-positive breast cancer patients treated with adjuvant chemotherapy was $47.6 \%$ for patients younger than 50 years, and $43.6 \%$ for those between 50 and 69

\begin{tabular}{|c|c|c|}
\hline KARGER & (C) 2006 S. Karger GmbH, Freiburg & $\begin{array}{l}\text { Prof. Dr. Günther Steger } \\
\text { Medizinische Universität Wien }\end{array}$ \\
\hline $\begin{array}{l}\text { Fax +49 } 7614520714 \\
\text { E-mail Information@Karger.de } \\
\text { www.karger.com }\end{array}$ & $\begin{array}{l}\text { Accessible online at: } \\
\text { www.karger.com/brc }\end{array}$ & $\begin{array}{l}\text { Klinische Abteilung für Onkologie } \\
\text { Währinger Gürtel 18-20,1090 Wien, Austria } \\
\text { Tel. +43 } 1 \text { 40400-4457, Fax -6081 } \\
\text { E-mail guenther.steger@meduniwien.ac.at }\end{array}$ \\
\hline
\end{tabular}


years of age. The 10-year overall survival (OS) was 53.8 and $48.6 \%$, respectively.

Another recent overview analysis demonstrated a highly significant advantage of anthracycline-based therapy regimens over cyclophosphamide, methotrexate and 5-fluorouracil (CMF) in the adjuvant treatment of breast cancer [2]. For a long time, the most appropriate anthracycline-based adjuvant therapy regimen for use in standard clinical practice was not clearly defined. Now, 3 different regimens, namely the Canadian cyclophosphamide, epidoxorubicin and 5-fluorouracil (CEF) [3], the US Intergroup cyclophosphamide, doxorubicin and 5-fluorouracil (CAF) [4] and the UK sequence epidoxorubicin, CMF [5], are more active than classic CMF (oral cyclophosphamide days 1-14, intravenous methotrexate days 1 and 8, 5-fluorouracil) [6] in reducing the risk of relapse and death in breast cancer. In addition, administration of an anthracycline-based combination chemotherapy regimen for 6 months reduces the annual breast cancer death rate by approximately $38 \%$ in women under 50 years of age at presentation and by about $20 \%$ in women aged $50-69$ years at presentation.

\section{Taxanes}

The taxanes docetaxel and paclitaxel are established as 2 of the most active agents in the treatment of metastatic breast cancer [7-9] and have marked a new era in breast cancer chemotherapy. First-generation phase II and phase III trials showed that these compounds were active in anthracycline-resistant disease [10,11]. Second-generation phase III trials found that single-agent taxanes were at least as active as single-agent anthracyclines $[12,13]$. Other trials showed that the combination of anthracyclines and taxanes led to a better response rate and disease-free survival (DFS) rate than standard anthracycline-based therapies in patients with metastatic breast cancer $[14,15]$. Because of these promising results, taxanes were primarily incorporated into neoadjuvant treatment. Trial B-27 of the National Surgical Adjuvant Breast and Bowel Project (NSABP) demonstrated that the addition of 4 cycles of sequential, preoperative docetaxel to 4 cycles of preoperative doxorubicin and cyclophosphamide (AC) resulted in a significantly superior outcome relative to 4 cycles of $\mathrm{AC}$ alone in terms of clinical, overall and pathologic complete response (pCR) and breast-conserving surgery [16]. Some have criticized this result because of differences in duration of the neoadjuvant chemotherapy (4 vs. 8 therapy cycles) and suggested that the favorable results of the AC/docetaxel arm may be due to the delivery of additional cycles of chemotherapy rather than a taxane benefit. However, results of another trial comparing 8 cycles of preoperative CVAP (cyclophosphamide, vincristine, doxorubicin, prednisolone) chemotherapy with 4 cycles of CVAP followed by 4 cycles of docetaxel prior to surgery, suggest that the addition of the taxane is in- deed beneficial [17]. Because of the effectiveness of taxanes in the metastatic as well as in the neoadjuvant setting, studies were conducted to evaluate their potential in the adjuvant treatment. First trials have explored whether the addition of taxanes either sequentially or in combination with adjuvant anthracycline-based chemotherapy improves outcome for patients with early breast cancer.

2 trials demonstrated efficacy of adding 4 courses of a taxane (paclitaxel) sequentially after 4 cycles of adjuvant chemotherapy in the adjuvant setting in node-positive breast cancer patients. In the NSABP B-28 trial [18], 3,059 patients with invasive breast cancer and at least 1 positive axillary lymph node on pathological examination were included. Patients assigned to the control arm received 4 cycles of $\mathrm{AC}$ (doxorubicin $60 \mathrm{mg} / \mathrm{m}^{2}$ and cyclophophamide $600 \mathrm{mg} / \mathrm{m}^{2}$ ) and patients in the experimental arm received 4 cycles of AC followed by 4 cycles of paclitaxel $225 \mathrm{mg} / \mathrm{m}^{2}$. Tamoxifen administration started on the first day of chemotherapy to all patients $\geq 50$ years of age, as well as to younger women with estrogen receptor-positive tumors. Results after a median follow-up of 64.6 months demonstrated that the addition of 4 cycles of paclitaxel significantly reduced DFS (reduction in the hazard rate of recurrence $17 \%, p=0.006$ ) without statistical significant improvement in the OS (reduction in the hazard rate of death $7 \%, p=0.46)$. The second study conducted by the Cancer and Leukemia Group B (CALGB) 9344 [19] randomized 3,121 women with operable breast cancer and lymph node involvement to receive a combination of cyclophosphamide $600 \mathrm{mg} / \mathrm{m}^{2}$ with 1 of 3 doses of doxorubicin, 60,75 or $90 \mathrm{mg} / \mathrm{m}^{2}$, for 4 cycles, followed by either no further therapy or 4 cycles of paclitaxel at $175 \mathrm{mg} / \mathrm{m}^{2}$. Tamoxifen treatment was recommended for all patients with hormone receptor-positive tumors starting after completion of adjuvant chemotherapy. There was no evidence of a doxorubicin dose effect. CALGB 9344 demonstrated that after 69 months of median follow-up the addition of paclitaxel improved DFS (reduction in the hazard rate of recurrence $17 \%, \mathrm{p}=0.0023$ ) and OS (reduction in the hazard rate of death $18 \%, \mathrm{p}=0.0064)$. The additional toxicity deriving from the sequential use of paclitaxel was generally modest. It is possible that the benefits observed in these 2 studies might be due to the administration of more cycles of chemotherapy in the experimental arm (8 cycles) compared with the standard arm (4 cycles).

A further 2 adjuvant taxane-containing trials, Breast Cancer International Research Group (BCIRG 01) [20] and Programme Adjuvant Cancer du Seins (PACS) 01 [21], provided important confirmatory information regarding the benefit of incorporating docetaxel, concomitantly or sequentially, in the adjuvant setting in node-positive breast cancer patients. BCIRG 01 [20] randomly assigned 1,491 patients with axillary node-positive operable breast cancer to 6 cycles of treatment with either 5 -fluorouracil $500 \mathrm{mg} / \mathrm{m}^{2}$, doxorubicin $50 \mathrm{mg} / \mathrm{m}^{2}$ and cyclophosphamide $500 \mathrm{mg} / \mathrm{m}^{2}$ (FAC) or doxorubicin $50 \mathrm{mg} / \mathrm{m}^{2}$, cyclophosphamide $500 \mathrm{mg} / \mathrm{m}^{2}$ and docetaxel 
Table 1. Definition of risk categories for patients with operated breast cancer

\begin{tabular}{|c|c|}
\hline Risk category & Definition \\
\hline Low risk ${ }^{\mathrm{a}}$ & $\begin{array}{l}\text { node-negative and all of the following features: } \mathrm{pT} \leq 2 \mathrm{~cm} \text {, and grade } 1^{\mathrm{b}} \text {, and absence of peritumoral vascular invasion }{ }^{\mathrm{c}} \text {, and } \\
\text { HER2 gene neither overexpressed nor amplified } \mathrm{d}^{\mathrm{d}} \text {, and age } \geq 35 \text { years }\end{array}$ \\
\hline Intermediate risk & $\begin{array}{l}\text { node-negative and at least } 1 \text { of the following features: } \mathrm{pT}>2 \mathrm{~cm} \text {, or grade } 2-3^{\mathrm{b}} \text {, or presence of peritumoral vascular } \\
\text { invasion }^{\mathrm{c}} \text {, or HER } 2 \text { gene overexpression or amplification }{ }^{\mathrm{d}} \text {, or age }<35 \text { years } \\
\text { node-positive (1-3 involved nodes) and HER } 2 \text { gene neither overexpressed nor amplified }\end{array}$ \\
\hline High risk & $\begin{array}{l}\text { node-positive (1-3 involved nodes) and HER } 2 \text { gene overexpressed or amplified } \\
\text { node-positive ( } 4 \text { or more involved nodes) }\end{array}$ \\
\hline \multicolumn{2}{|c|}{$\begin{array}{l}\text { a Some panel members view pT1a and pT1b (i.e. pT }<1 \mathrm{~cm} \text { ) tumors with node-negative disease as representing low risk even with higher grades } \\
\text { and/or younger age. } \\
\text { bHistologic and/or nuclear grade. } \\
\text { cPeritumoral vascular invasion was considered controversial as a discriminatory feature of increased risk; its presence defined intermediate risk for } \\
\text { node-negative disease but did not influence risk category for node-positive disease. } \\
{ }^{\mathrm{d}} \mathrm{HER} 2 \text { gene overexpression or amplification must be determined by quality-controlled assays using immunhistochemistry or fluorescence in situ } \\
\text { hybridization analysis. }\end{array}$} \\
\hline
\end{tabular}

$75 \mathrm{mg} / \mathrm{m}^{2}$ (TAC) as adjuvant chemotherapy after surgery. Tamoxifen for 5 years was recommended for all patients with hormone receptor-positive tumors, beginning at the end of adjuvant chemotherapy. At a median follow-up of 55 months, the estimated DFS rates at 5 years were $75 \%$ among the 745 patients randomly assigned to receive TAC and $68 \%$ among the 746 randomly assigned to receive FAC, representing a $28 \%$ reduction in the risk of relapse $(\mathrm{p}=0.001)$ in the TAC group. The estimated OS rates at 5 years were 87 and $81 \%$, respectively. Treatment with TAC resulted in a $30 \%$-reduction in the risk of death $(\mathrm{p}=0.008)$. In the subgroup analysis that included the number of involved axillary lymph nodes, HER2 status and hormone receptor status, TAC was superior to FAC, independent of menopausal status. In the PACS 01 trial [21], 1,999 patients with node-positive operable breast cancer were randomized to either 6 cycles of 5-fluorouracil $500 \mathrm{mg} / \mathrm{m}^{2}$, epidoxorubicin $100 \mathrm{mg} / \mathrm{m}^{2}$ and cyclophosphamide $500 \mathrm{mg} / \mathrm{m}^{2}$ (FEC100) or 3 cycles of FEC100 followed by 3 cycles of docetaxel $100 \mathrm{mg} / \mathrm{m}^{2}($ FEC $\times 3$-Docetaxel $\times 3)$. At a median follow-up period of 60 months, adjuvant chemotherapy with 3 cycles of FEC100 followed by 3 cycles of docetaxel improved recurrence-free survival (reduction in the hazard rate of recurrence, $17 \%, \mathrm{p}=0.04$ ) and OS (reduction in the hazard rate of death, $23 \%, p=0.005$ ). The superiority of the sequential docetaxel treatment over 6 FEC100 was observed in a subgroup analysis that included the number of involved axillary lymph nodes and hormone receptor status. Concerning the toxicities, application of granulocyte-colony stimulating factor (G-CSF) for primary prophylaxis was not permitted in the BCRIG 01 as well as in the PACS 01 study. This led in the BCRIG trial to a high incidence of severe neutropenia and even febrile neutropenia in patients assigned to the TAC regimen. In contrast, the incidence of febrile neutropenia, infection and cardiac dysfunction was lower in the sequential
FEC $\times 3$-Docetaxel $\times 3$ arm of the PACS 01 study as compared to the standard FEC100 arm [20, 21].

Another dosing strategy under active investigation is dosedense therapy. The first clinical trial to demonstrate survival benefits associated with dose-dense therapy was the CALGB 9741 trial [22]. CALGB 9741 included axillary node-positive breast cancer patients using a $2 \times 2$ factorial design to compare sequential doxorubicin, paclitaxel and cyclophosphamide with concurrent AC followed by paclitaxel as well as both arms in a dose-dense therapy regimen. 2,005 patients were assigned to 1 of 4 treatment regimens: I) doxorubicin $60 \mathrm{mg} / \mathrm{m}^{2}$ every 3 weeks for 4 cycles followed by paclitaxel $175 \mathrm{mg} / \mathrm{m}^{2}$ every 3 weeks for 4 cycles followed by cyclophosphamide $600 \mathrm{mg} / \mathrm{m}^{2}$ every 3 weeks for 4 cycles; II) doxorubicin $60 \mathrm{mg} / \mathrm{m}^{2}$ every 2 weeks for 4 cycles followed by paclitaxel $175 \mathrm{mg} / \mathrm{m}^{2}$ every 2 weeks for 4 cycles followed by cyclophosphamide $600 \mathrm{mg} / \mathrm{m}^{2}$ every 2 weeks for 4 cycles, with filgrastim on days 3-10 of each cycle; III) doxorubicin $60 \mathrm{mg} / \mathrm{m}^{2}$ plus cyclophosphamide $600 \mathrm{mg} / \mathrm{m}^{2}$ every 3 weeks for 4 cycles followed by paclitaxel $175 \mathrm{mg} / \mathrm{m}^{2}$ every 3 weeks for 4 cycles; IV) doxorubicin $60 \mathrm{mg} / \mathrm{m}^{2}$ plus cyclophosphamide $600 \mathrm{mg} / \mathrm{m}^{2}$ every 2 weeks for 4 cycles followed by paclitaxel $175 \mathrm{mg} / \mathrm{m}^{2}$ every 2 weeks for 4 cycles with filgrastim on days 3-10 of each cycle. At a median follow-up of 36 months, dose-dense treatment improved DFS $(p=0.01)$ and OS $(p=0.013)$. There was no difference in DFS and OS between the concurrent and sequential schedule. Severe neutropenia was less frequent in patients who received the dose-dense regimens.

Hence, taxane-containing therapy regimens improve outcome for patients with breast cancer in the metastatic, adjuvant and neoadjuvant setting. The adjuvant studies demonstrated that by adding a taxane to an anthracycline-based therapy regimen DFS and OS can be improved. However, there may be an additional effect of taxane-containing therapy regimens. Pre- 
menopausal estrogen receptor-positive patients benefit from the cytotoxic and endocrine effect of receiving adjuvant chemotherapy. Conversely, in premenopausal estrogen receptor-negative patients, the benefit derived from this treatment modality is dependent on its cytotoxic effect. In postmenopausal patients, administration of adjuvant chemotherapy has no endocrine effect, and therefore reductions in the risk of relapse and death derive only from the cytotoxic effects. The EBCTCG analysis [1] demonstrated that in postmenopausal patients, the proportional reduction in the risk of recurrence associated with the use of chemotherapy was 18 and $30 \%$ in estrogen receptor-positive and estrogen receptornegative tumors, respectively. The proportional reduction in the risk of death in postmenopausal patients receiving chemotherapy is smaller in the case of estrogen receptor-positive tumors $(9 \%)$ than in estrogen receptor-negative $(17 \%)$ tumors. Nearly $50 \%$ of patients participating in the adjuvant taxane-comparing trials were premenopausal at the time of randomization. Therefore, we must expect that the endocrine effect of the taxane-based treatment might interfere with the observed results. The 33-month interim analysis of the BICRG 01 trial reported that incidence of chemotherapy-related amenorrhea is higher in the taxane than in the anthracycline-based treatment arm [20].

In the adjuvant setting, the optimal patient population to administer a taxane-containing therapy regimen is still under evaluation. However, the 9th St. Gallen Consensus Panel defined low-, intermediate- and high-risk categories depending on the nodal status in patients with early breast cancer [23] (table 1). Within these defined categories, adequate adjuvant treatment should be dependent on the endocrine responsive disease. The panel defined that the application of adjuvant chemotherapy in the intermediate-risk group should be offered to all patients with endocrine non-responsive disease and to some patients with endocrine responsive disease or disease of uncertain endocrine responsiveness in addition to en- docrine treatment. All patients in the high-risk group are likely to receive adjuvant chemotherapy unless it is contraindicated or rejected by patient preference. For high-risk patients with endocrine responsive disease, treatment with 4 courses of AC was considered to be appropriate. Most panelists did not support taxane-containing treatments in this population regardless of their nodal status. Also, for patients with endocrine non-responsive disease and intermediate risk, an anthracycline-containing regimen was favored, but the use of a taxane-containing regimen may also be possible. Taxanes were encouraged for higher-risk patients with endocrine non-responsive disease.

\section{Conclusion}

We already know that administering docetaxel instead of 5-fluorouracil, i.e. changing the FAC to the TAC regimen, and substituting 3 cycles of FEC100 with 3 cycles of docetaxel leads to a superior effect with respect to DFS and OS rates in patients with early breast cancer. The latter regimen is also associated with a significant decrease of clinically relevant side effects, such as febrile neutropenia and cardiac dysfunction, as compared to the widely used standard adjuvant treatment with 6 cycles of FEC100 for node-positive breast cancer. Similarly, applying dose-dense paclitaxel-based therapy in which chemotherapy cycles are administered every 2 weeks by use of G-CSF, has produced impressive preliminary results in the adjuvant setting, while the results of confirmatory trials are still pending. It remains to be determined if dose-dense application of docetaxel will be as effective as dose-dense paclitaxel. But many questions remain unanswered, including whether the use of taxanes should be sequential or concomitant and which population would benefit from such a treatment. Therefore, further randomized adjuvant trials are necessary to respond the open questions.

\section{References}

1 Early Breast Cancer Trialist's Collaborative Group Polychemotherapy for early breast cancer: an overview of the randomized trials. Lancet 1998;352: 930-942.

$\checkmark 2$ Early Breast Cancer Trialist's Collaborative Group: Effects of chemotherapy and hormonal therapy for early breast cancer on recurrence and 15 -year survival: an overview of the randomized trials. Lancet 2005;365:1687-1717.

3 Levine MN, Bramwell VH, Pritchard KI, et al.: Randomized trial of intensive cyclophophamide, epirubicin, and fluorouracil chemotherapy compared with cyclophosphamide, methotrexate, and fluorouracil in premenopausal women with nodepositive breast cancer: National Cancer Institute of Canada Clinical Trials Group. J Clin Oncol 1998;16: 2651-2658.
4 Hutchins L, Green S, Ravdin P, et al.: CMF versus CAF with and without tamoxifen in high-risk nodenegative breast cancer patients: first results of intergroup trial INT 0102. Proc Am Soc Clin Oncol 1998;17a:1a (abstr 2).

5 Poole CJ, Earl HM, Dunn JA, et al.: NEAT (National Epirubicin Adjuvant Trial), and SCTBG BR9601 (Scottish Cancer Trials Breast Group) phase III adjuvant breast trials show a significant relapse-free and overall survival advantage for sequential ECMF. Proc Am Soc Clin Oncol 2003;22:4 (abstr 13).

6 Bonadonna G, Moliterni A, Zambetti M, et al.: 30 years' follow up of randomised studies of adjuvant CMF in operable breast cancer: cohort study. BMJ 2005;330:217.

7 Seidman AD, Tiersten A, Hudis C, et al.: Phase II trial of paclitaxel by 3-hour infusion as initial and salvage chemotherapy for metastatic breast cancer. J Clin Oncol 1995;13:2575-2581.
8 Seidman AD, Reichman BS, Crown JP, et al.: Paclitaxel as second and subsequent therapy for metastatic breast cancer: activity independent of prior anthracycline response. J Clin Oncol 1995;13: 1152-1159.

9 Valero V, Holmes FA, Walters RS, et al.: Phase II trial of docetaxel: A new, highly effective antineoplastic agent in the management of patients with anthracycline-resistant metastatic breast cancer. J Clin Oncol 1995;13:2886-2894.

10 Holmes FA, Walters RS, Theriault RL, et al.: Phase II trial of taxol, an active drug in the treatment of metastatic breast cancer. J Natl Cancer Inst 1991; 83:1797-1805.

11 Nabholtz JM, Senn HJ, Bezwoda WR, et al.: Prospective randomised trial of docetaxel versus mitomycin plus vinblastin in patients with metastatic breast cancer progressing despite previous anthracycline-containing chemotherapy. J Clin Oncol 1999;17:1413-1424. 
12 Chan S, Friedrichs K, Noel D, et al.: Prospective randomised trial of docetaxel versus doxorubicin in patients with metastatic breast cancer. J Clin Oncol 1999;17:2341-2354.

13 Sledge GW, Neuberg D, Bernardo P, et al.: Phase III trial of doxorubicin, paclitaxel, and the combination of doxorubicin and paclitaxel as front-line chemotherapy for metastatic breast cancer: an Intergroup trial (E1193). J Clin Oncol 2003;21: 588-592.

14 Nabholtz JM, Falkson C, Campos D, et al.: Docetaxel and doxorubicin compared with doxorubicin and cyclophosphamide as first-line chemotherapy for metastatic breast cancer: results of a randomized, multicenter, phase II trial. J Clin Oncol 2003; 21:968-975.

15 Biganzoli L, Cufer T, Bruning P, et al.: Doxorubicin and paclitaxel versus doxorubicin and cyclophosphamide as first-line chemotherapy in metastatic breast cancer: The European Organization for Research and Treatment of Cancer 10961 multicenter phase II trial. J Clin Oncol 2002;20:3114-3121.

16 Bear HD, Anderson S, Brown A, et al.: The effect on tumor response of adding sequential preoperative docetaxel to preoperative doxorubicin and cyclophosphamide: preliminary results from National Surgical Adjuvant Breast and Bowel Project Protocol B-27. J Clin Oncol 2003;21:4165-4174.

17 Smith IC, Heys SD, Hutcheon AW, et al.: Neoadjuvant chemotherapy in breast cancer: significantly enhanced response with docetaxel. J Clin Oncol 2002;20:1456-1466.

18 Mamounas EP, Bryant J, Lembersky B, Fehrenbacher L, Sedlacek SM, Fisher B, Wickerham DL, Yothers G, Soran A, Wolmark N: Paclitaxel after doxorubicin plus cyclophosphamide as adjuvant chemotherapy for node-positive breast cancer: results from NSABP B-28. J Clin Oncol 2005;23: 3686-3696.

19 Henderson IC, Berry DA, Demetri GD, Cirrincione CT, Goldstein LJ, Martino S, Ingle JN, Cooper MR, Hayes DF, Tkaczuk KH, Fleming G, Holland JF, Duggan DB, Carpenter JT, Frei III E, Schilsky RL, Wood WC, Muss HB, Norton L: Improved outcomes from adding sequential paclitaxel but not from escalating doxorubicin dose in an adjuvant chemotherapy regimen for patients with node-positive primary breast cancer. J Clin Oncol 2003;21:976-983.

20 Martin M, Pienkowski T, Mackey J, et al.: Adjuvant docetaxel for node-positive breast cancer. N Engl J Med 2005;352:2302-2313.

21 Roche H, Fumoleau P, Spielmann M, et al.: 6 cycles of FEC 100 vs. 3 FEC 100 followed by 3 cycles of docetaxel for node-positive breast cancer patients: analysis at 5 years of the adjuvant PACS 01 trial. SABCS 2005;27a:27(abstr).

22 Citron ML, Berry DA, Cirrincione C, et al.: Randomized trial of dose-dense versus conventionally scheduled and sequential versus concurrent combination chemotherapy as postoperative adjuvant treatment of node-positive primary breast cancer: first report of Intergroup trial C 9741 / Cancer and Leukemia Group B Trial 9741. J Clin Oncol 2003; 21:1431-1439.

-23 Goldhirsch A, Glick JH, Gelber RD, Coates AS, Thürlimann B, Senn HJ, and panel members: Meeting highlights: International Expert Consensus on the primary therapy of early breast cancer 2005 . Ann Oncol 2005;16:1569-1583. 